\title{
Putative cancer stem cells may be the key target to inhibit cancer cell repopulation between the intervals of chemoradiation in murine mesothelioma
}

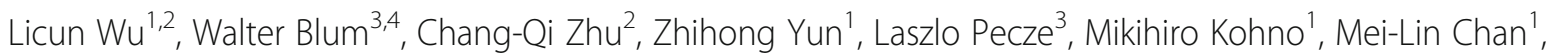
Yidan Zhao ${ }^{1}$, Emanuela Felley-Bosco ${ }^{5}$, Beat Schwaller ${ }^{3}$ and Marc de Perrot ${ }^{1,2,6^{*}}$

\begin{abstract}
Background: Cancer cell repopulation during chemotherapy or radiotherapy is a major factor limiting the efficacy of treatment. Cancer stem cells (CSC) may play critical roles during this process. We aim to demonstrate the role of mesothelioma stem cells (MSC) in treatment failure and eventually to design specific target therapies against MSC to improve the efficacy of treatment in malignant mesothelioma.

Methods: Murine mesothelioma AB12 and RN5 cells were used to compare tumorigenicity in mice. The expression of CSC-associated genes was evaluated by quantitative real-time PCR in both cell lines treated with chemo-radiation. Stemness properties of MSC-enriched RN5-EOS-Puro2 cells were characterized with flow cytometry and immunostaining. A MSCspecific gene profile was screened by microarray assay and confirmed thereafter. Gene Ontology analysis of the selected genes was performed by GOMiner.

Results: Tumor growth delay of murine mesothelioma AB12 cells was achieved after each cycle of cisplatin treatment, however, tumors grew back rapidly due to cancer cell repopulation between courses of chemotherapy. Strikingly, a 10-times lower number of irradiated cells in both cell lines led to a similar tumor incidence and growth rate as with untreated cells. The expression of CSC-associated genes such as CD24, CD133, CD90 and uPAR was dramatically up-regulated, while others did not change significantly after chemoradiation. Highly enriched MSC after selection with puromycin displayed an increasing GFP-positive population and showed typical properties of stemness. Comparatively, the proportion of MSC significantly increased after RN5-EOS parental cells were treated with either chemotherapy, Y-ray radiation, or a combination of the two, while MSC showed more resistance to the above treatments. A group of identified genes are most likely MSC-specific, and major pathways related to regulation of cell growth or apoptosis are involved. Upregulation of the gene transcripts Tnfff18, Serpinb9b, Ly6a, and Nppb were confirmed.
\end{abstract}

Conclusion: Putative MSC possess the property of stemness showing more resistance to chemoradiation, suggesting that MSC may play critical roles in cancer cell repopulation. Further identification of selected genes may be used to design novel target therapies against MSC, so as to eliminate cancer cell repopulation in mesothelioma.

Keywords: Mesothelioma stem cell (MSC), RN5-EOS-Puro2 cells, Cancer cell repopulation, Microarray, Chemoradiation

\footnotetext{
* Correspondence: marc.deperrot@uhn.ca

'Division of Thoracic Surgery, Latner Thoracic Surgery Laboratories, University

Health Network, Toronto, ON, Canada

${ }^{2}$ Princess Margaret Cancer Centre, University Health Network, Toronto, ON,

Canada

Full list of author information is available at the end of the article
}

(c) The Author(s). 2018 Open Access This article is distributed under the terms of the Creative Commons Attribution 4.0 International License (http://creativecommons.org/licenses/by/4.0/), which permits unrestricted use, distribution, and reproduction in any medium, provided you give appropriate credit to the original author(s) and the source, provide a link to the Creative Commons license, and indicate if changes were made. The Creative Commons Public Domain Dedication waiver (http://creativecommons.org/publicdomain/zero/1.0/) applies to the data made available in this article, unless otherwise stated. 


\section{Background}

Malignant pleural mesothelioma (MPM) is a highly aggressive malignancy with poor prognosis, most often associated with long-term exposure to asbestos [1]. However, limited efficacy of conventional chemotherapy, radiotherapy and surgery drives investigators to explore novel approaches to treat this disease [2-4].

Over the past decade, a number of clinical trials has been conducted looking at a tri-modality approach using induction chemotherapy, followed by surgery with an extrapleural pneumonectomy (EPP) and adjuvant hemithoracic radiation [5-7]. We have developed an innovative approach for MPM treatment with a short accelerated course of high-dose hemi-thoracic intensity-modulated radiation therapy followed by EPP. The initial phase I/II study assessed the feasibility of Surgery for Mesothelioma After Radiation Therapy (SMART). This innovative protocol SMART yields encouraging results and supports future studies looking at long-term outcome in patients with epithelioid MPM subtypes [8].

Here, we focus on immune modulation to trigger immune responses against mesothelioma stem cells (MSC) during the intervals of cytotoxic therapy. Evidence supports the notion that cancer cell repopulation can be attributed to cancer stem cells due to their higher resistance to conventional therapy and that this phenomenon could be inhibited or eliminated by a $\mathrm{T}$ cell response.

Our previous translational work showed that an antitumor effect through modulation of specific $\mathrm{T}$ cell responses may be achieved in murine model systems. For example, activation of natural killer $\mathrm{T}$ cells, depletion of regulatory $\mathrm{T}$ (Treg) cells, or systemic blockade of the immune checkpoint inhibitory regulator of T-cell immunity CTLA-4, between cycles of chemotherapy, was shown to inhibit cancer cell repopulation by enhancing specific antitumor immunity in murine mesothelioma [9-13]. We also demonstrated that anti-CTLA4 treatment can promote the abscopal effect to distant tumor sites after the primary tumor received local radiation [14]. Cancer cell repopulation can be inhibited or eliminated by $\mathrm{T}$ cell responses, suggesting that resistance to conventional therapy may be related to CSC escaping the immune system [15-20].

Thus, it would be beneficial to target MSC, if they could be unambiguously identified. However, the biggest challenge to target MSC is the lack of specific markers to identify them [21]. Since the MSC population is rather small among all tumor cells (estimated to be less than $5 \%$ in most cases), it remains a big hurdle to accumulate and isolate a large number of putative MSC, even if cell sorting can be used; the isolation procedure is time- and labour-consuming. Isolation of sphereforming cells [22] has limitations as well, since those cells may initiate from CSC, but don't necessarily have to be composed entirely of CSC [23].
The idea on how to achieve isolation of a large number of putative MSC comes from stem cell biology. The method was initially used to select induced pluripotent stem cells (iPS) with the help of an EOS (Early transposon Oct4 and Sox 2 enhancer) system as a vector by selecting Sox 2 and Oct4-expressing cells. The plasmid construct has Sox2- and Oct4-binding sites in the promoter region, which then drives GFP expression. The plasmid also contains a puromycin resistance gene that allows to identify subpopulations in the murine mesothelioma cell line RN5-EOS characterized by high levels of EOS reporter activity [24]. In the whole population of RN5-EOS cells approximately 5\% of cells show GFP expression [25]. The selection with puromycin allows for the enrichment of the putative MSC named RN5-EOSPuro2 [26]. Indeed, putative MSC are approximately 50$70 \%$ GFP-positive $\left(\mathrm{GFP}^{+}\right)$after 7 days of selection. Thus, we consider the high yield of putative MSC as a requirement for identification of stem cell markers and preparation of putative MSC lysates to design novel target therapies.

\section{Methods \\ Cell lines}

The murine mesothelioma cell line RN5 derived from C57Bl/6 mice was established recently by our team [27] and the cell line AB12 (from Balb/c mice) was kindly provided by Dr. Jay Kolls, University of Pittsburgh, Pittsburgh, PA. Both cell lines were maintained in RPMI 1640 medium supplemented with $10 \%$ fetal bovine serum and $1 \%$ penicillin and streptomycin, and maintained at $37{ }^{\circ} \mathrm{C}$ in an atmosphere containing $5 \% \mathrm{CO}_{2}$. Cells were treated prophylactic with $5 \mu \mathrm{g} / \mathrm{ml}$ Plasmocin ${ }^{\mathrm{Tm}}$ (Invivogen) for at least 2 weeks and were confirmed as mycoplasma-free. Cells were used for experiments at the time point of exponential growth (approximate 90\% confluence) for all experiments.

Details on the generation of RN5-EOS-Puro2 cells have been described before [25]. Briefly, the method was initially used to select for induced pluripotent stem cells (iPS) with the help of an EOS (Early transposon Oct4 and Sox2 enhancer) system as part of the vector. The plasmid construct has Sox2- and Oct4-binding sites in the promoter region, which then drives GFP expression and furthermore contains a puromycin resistance separated by an IRES. Puromycin $(2 \mu \mathrm{g} / \mathrm{ml}$; Life Technologies, China) was used for the selection process. This technique allowed us to identify the RN5 subpopulations characterized by high activity of the reporter, which was enriched for tumor initiating activity [24]. As the overall design in this study is depicted in Fig. 1, we compared these cells to murine mesothelioma RN5 cells treated with conventional therapy (cisplatin or $\gamma$-ray radiation), where surviving tumor cells were collected for further experiments to evaluate tumorigenicity and gene expression. 


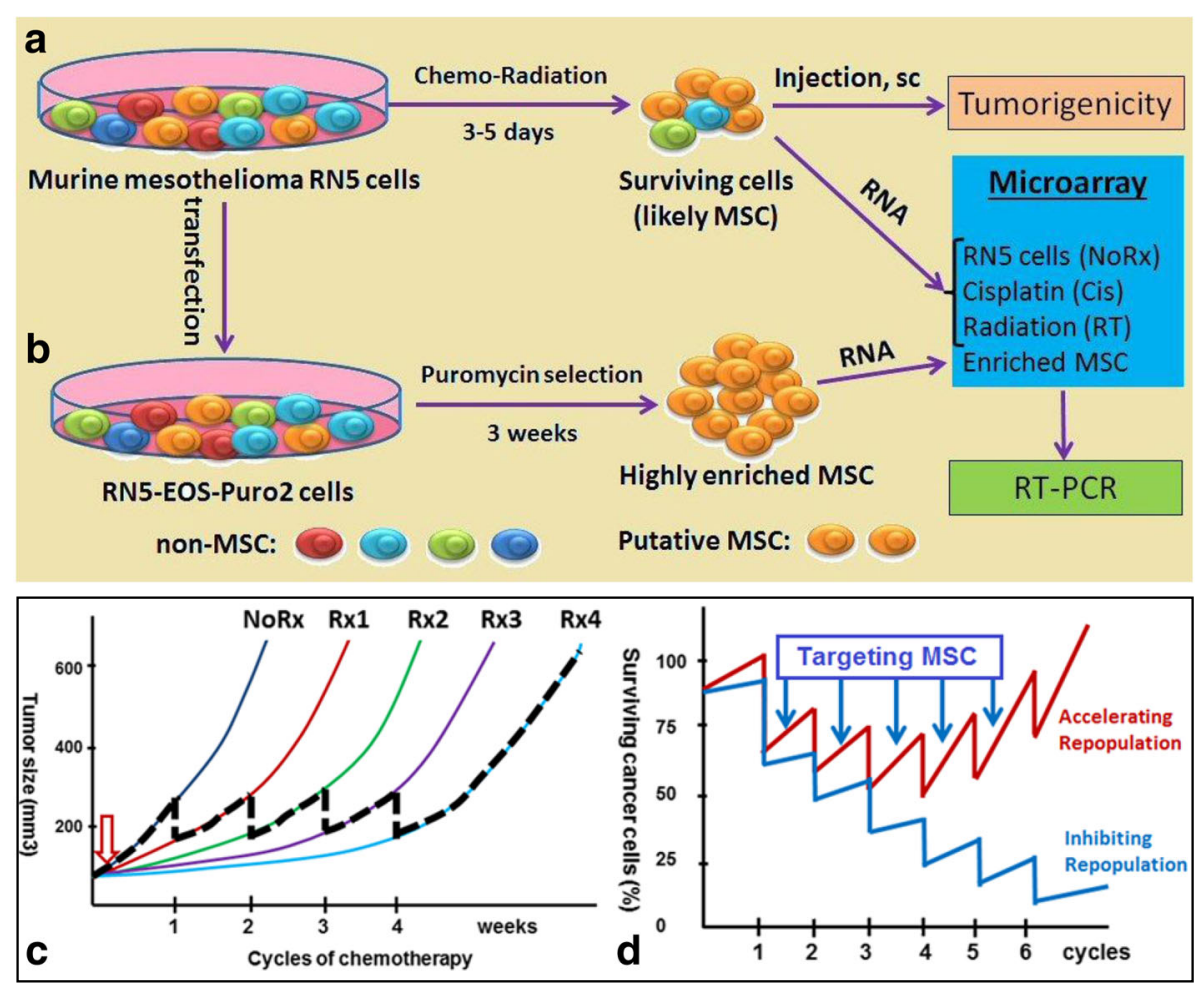

Fig. 1 Experimental design and long-term goal of this study. Cancer cell repopulation during courses of chemotherapy and possibly mesothelioma stem cells (MSC) might play critical roles in tumor relapse. a Murine mesothelioma RN5 cells were treated with conventional therapy (cisplatin or $\gamma$-ray radiation) and surviving cells were collected for further experiments to evaluate tumorigenicity and gene expression profiles; $\mathbf{b}$ RN5 cells were transduced with lentivirus and selected with puromycin resulting in RN5-EOS-P2 cells enriched in MSC. Microarray analysis was performed to screen for gene profiles specific for MSC. c AB12 tumor growth in Balb/c mice after treatment with cisplatin once weekly, $5 \mu \mathrm{g} / \mathrm{kg}$ body weight, up to 4 cycles (Rx1-4) to mimic clinical settings ( $n=5$ mice). Tumor growth delay was achieved by each cycle of chemotherapy, however, tumors grew back rapidly due to cancer cell repopulation between courses of weekly chemotherapy. NoRx: no treatment, Rx1-4: number of doses of cisplatin; $\mathbf{d}$ Modeling the effects of specific MSC targeting: the model is based on the assumption that targeting MSC would delay/prevent tumor repopulation during the intervals of chemotherapy (blue curve) in comparison to conventional treatment (red curve) that mostly targets non-MSC

Incidence of syngeneic mesothelioma cell-derived tumors in mice

RN5 and AB12 cells treated with $\gamma$-ray irradiation of 15Gy $\left(10^{4}\right.$ and $10^{5}$ cells, as indicated in the figure legend) were injected subcutaneously (s.c.) into the right flank of 6-8 week-old female C57BL/6 and Balb/c mice, respectively, both mouse strains purchased from The Jackson Laboratory (Bar Harbor, Maine), while the untreated parental cells $\left(10^{5}\right.$ and $10^{6}$ cells) were injected respectively into the right flank of other mice as controls. The tumor incidence and tumor growth curves were plotted according to the maximal perpendicular diameters as a function of days after tumor challenge. When tumors grew to the designated size (5 $\mathrm{mm}$ in diameter), the two maximal perpendicular diameters were measured with a calliper twice weekly to evaluate tumor incidence and growth. At the end points mice were sacrificed in accordance to the euthanasia guidelines of the Animal Use Protocol (AUP\# 3399), which was approved by the
Animal Resources Centre of University Health Network (UHN), Toronto, Canada.

\section{Treatment of cells and RNA extraction}

Parental RN5-EOS cells and highly enriched MSC RN5EOS-Puro 2 cells $\left(10^{6}\right.$ cells $/ 5 \mathrm{ml} /$ well in a 6 -well plate) were treated with cisplatin (Onco-Tain ${ }^{\text {тм }}$ Hospira, UK) either with 0,1 or $5 \mu \mathrm{g} / \mathrm{ml}$ overnight, or $\gamma$-ray radiation 5 Gy and $15 \mathrm{~Gy}$ by Cs-137 Gamma Cell Irradiator-40 (Atomic Energy of Canada Ltd., Ottawa, Canada) at a dose rate of approximately $100 \mathrm{cGy} / \mathrm{min}$. Surviving cells were collected after overnight culture and used to extract RNA; dead floating cells and cell debris were washed away. The procedure of RNA extraction was performed according to the manufacturer's instruction (QIAGEN, RNeasy Microarray Tissue Mini Kit, CA). Total RNA was treated with a Purelink DNase set (Thermo Fisher Sci., CA). RNA was used for cDNA synthesis using the Cloned AMV FirstStrand cDNA Synthesis Kit (Thermo fisher Sci., CA). 
Gene expression was evaluated by real-time PCR or microarray assay.

\section{Real-time PCR}

The oligos of previously reported CSC-associated genes and their oligo sequences $\left(5^{\prime}-3^{\prime}\right)$ are composed as follows:

\begin{tabular}{|c|c|}
\hline Genes & Primer sequence $5^{\prime}-3^{\prime}$ \\
\hline \multirow[t]{2}{*}{ CD24 } & F CTGCTTCTGGCACTGCTCCTA \\
\hline & R CGGTGCAACAGATGTTTGGT \\
\hline \multirow[t]{2}{*}{ CD34 } & F ACCCACCGAGCCATATGCT \\
\hline & R CAGATACCCTGGGCCAACCT \\
\hline \multirow[t]{2}{*}{ CD68 } & F CTGCTCAGCTGCCTGACAAG \\
\hline & R CCAATGATGAGAGGCAGCAA \\
\hline \multirow[t]{2}{*}{ UPAR } & F GGCGACTACCTGTGTCCCA \\
\hline & R CTCCTCTACCAGGCAGCTCTG \\
\hline \multirow[t]{2}{*}{ CD90 } & F ACCATGAACCCAGCCATCA \\
\hline & R CTCGGGACACCTGCAAGACT \\
\hline \multirow[t]{2}{*}{ Bmi1 } & F TGATCAGAGCAGATTGGATCG \\
\hline & R GCTGCTGGGCATCGTAAGT \\
\hline \multirow[t]{2}{*}{ CD117 } & F GCCAGTGCTTCCGTGACAT \\
\hline & R GTCGTACGTCAGGATTTCTGGTT \\
\hline \multirow[t]{2}{*}{ CD133 } & F CGTGCTGGGAGGCAGAATA \\
\hline & R GGGCATCCTTGGTCTGTTTG \\
\hline \multirow[t]{2}{*}{ Tnfsf18 } & F AAGGGCAGAGAGGTGCAAGAA \\
\hline & R TGCAGGACTCGATGGCAGTT \\
\hline \multirow[t]{2}{*}{ Serpinb9b } & F TATGGTCCTCCTGGGTGCAA \\
\hline & R TGTCTGGCTTGTTCAGCTTCCT \\
\hline \multirow[t]{2}{*}{ Ly6a (Sca-1) } & F CTGCCCCTACCCTGATGGA \\
\hline & R GGGCAGATGGGTAAGCAAAGA \\
\hline \multirow[t]{2}{*}{$\mathrm{Nppb}$} & F GGTGACACATATCTCAAGCTGCTIT \\
\hline & R CAGCCAGGAGGTCTTCCTACAA \\
\hline
\end{tabular}

Quantitative PCR was performed according to a protocol previously reported [14].

Based on microarray-screened common genes, further confirmation of these genes was evaluated by real-time PCR. RN5 cells were treated with Cis $0.5 \mu \mathrm{g} / \mathrm{ml}$, and 1 . $0 \mathrm{mg} / \mathrm{ml}$, or RT $5 \mathrm{~Gy}, 10 \mathrm{~Gy}$, and $15 \mathrm{~Gy}$, and harvested after 3 days to remove dead cells. RNA was extracted as stated before.

\section{Flow cytometry}

RN5-EOS parental cells and RN5-EOS-Puro2 MSC were treated with cisplatin $(1-5 \mu \mathrm{g} / \mathrm{ml})$ overnight or/and $\gamma$-ray radiation $5 \mathrm{~Gy}$ and $15 \mathrm{~Gy}$; cells were washed to remove dead cells and cell debris after overnight culture. All surviving cells were harvested and quantitated for the presence of $\mathrm{GFP}^{+}$populations by flow cytometry.
The presence of Tnfsf18, Ly6a (Sca-1), and CD90 was confirmed with staining of cells by monoclonal antibodies.

A Becton Dickinson LSR II Flow Cytometer (San Jose, CA) and FACS Diva ${ }^{\text {Tw }}$ software were used for analyses and data acquisition; FlowJo ${ }^{\text {Tm }}$ software was used for analysis.

\section{Immunofluorescence staining}

MSC with or without treatment were harvested after washing with PBS and cultured in an 8-well Nunc ${ }^{\circ}$ lab-Tek $^{\circ}$ chamber slide ${ }^{\mathrm{sm}}$ system (sigma-Aldrich) overnight. Slides were prepared for immunofluorescence staining with anti-GFP antibody conjugated with Alexa-488 and primary antibody rat anti-mouse $\beta$-actin (1:200); the secondary antibody anti-rat IgG-Alexa555 and DAPI (cell signaling) were applied following the manufacturer's instructions. Fluorescence images of whole slides were captured by a Nikon inverse microscope $(60 \times$ or $100 \times$, NA 1.4, oil immersion objectives) connected with a Yokogawa spinning disk confocal system with Zeiss Axiovert $200 \mathrm{M}$ inverted microscope (Gottingen, Germany). Images were acquired using the Volocity software (Waltham, MA).

\section{Microarray data analysis}

RN5 cells growing in the exponential phase were harvested and treated in 6-well plates $\left(10^{6}\right.$ cells $/ 5 \mathrm{ml} /$ well $)$. Four groups consisted of: 1) Parental RN5 cells without (no) treatment (NoRx), 2) RN5 cells treated with cisplatin $(1 \mu \mathrm{g} / \mathrm{ml})(\mathrm{Cis}), 3) \mathrm{RN} 5$ cells treated with $\gamma$-ray radiotherapy (5 Gy) (RT) and 4) RN5-EOS-Puro2 cells after puromycin selection to achieve enriched mesothelioma stem cells (MSC). Naïve peritoneum (N) was included as a negative control. Each group consisted of three samples. RNA was extracted as stated previously. Affymetrix Mouse Gene 2.0 microarray was performed to screen for potential mesothelioma or MSC-associated genes. Affymetrix Transcriptome Analysis Console (TAC) software (Santa Clara, CA) and Partek ${ }^{\odot}$ Genomics Suite ${ }^{\bullet}$ software (St. Luis, MI) were used for data analysis. Genes with at least 2 -fold changes were selected for further analysis. Comparisons among multiple groups were analyzed with ANOVA and differences were considered significant, if $P$ values were less than 0.05 .

Gene Ontology (GO) analysis was done using the GOMiner (https://discover.nci.nih.gov/gominer/htgm.jsp) web application. To expand the gene list of differentially expressed genes for a more stable gene ontology analysis, Pearson Correlation analysis (SAS v9.4, SAS Institute) was used to assess the correlated genes with the identified 41 genes and $0.98<r<-0.98$ and $p<0.00001$ were selected as the cutoffs. 
Overall experimental design and proposal of this study

Cancer cell repopulation during courses of chemotherapy and possibly MSC might play critical roles in tumor relapse. Murine mesothelioma RN5 cells were treated with conventional therapy (cisplatin or $\gamma$-ray radiation) and surviving cells were collected for further experiments to evaluate tumorigenicity and gene expression profiles (Fig. 1a); RN5 cells were transduced with lentivirus and selected with puromycin resulting in RN5-EOS-Puro2 cells enriched in MSC. Microarray analysis was performed to screen for gene profiles specific for MSC (Fig. 1b).

\section{Statistical analysis}

All data are presented as the mean \pm SEM. The comparison of gene expression and proportion of $\mathrm{T}$ cells between two groups was analyzed by using an unpaired Student's $t$ test. ANOVA was performed when compared among multiple groups using GraphPad Prism 6.0 statistical software (La Jolla, CA). A value of $P<0.05$ was considered significantly different for all comparisons. ${ }^{*} P<0.05$; ** $P<0.01$; ** $P<0.001$; **** $P<0.0001$.

\section{Results}

Mesothelioma stem cells (MSC) may play a critical role in cancer cell repopulation during weekly cycles of chemotherapy and thus serve as a potential target

Murine mesothelioma AB12-derived tumors were treated with chemotherapy once weekly to mimic clinical settings. A tumor growth delay was achieved with each cycle of chemotherapy: however, tumors grew back rapidly due to cancer cell repopulation between the courses of weekly chemotherapy (Fig. 1c). Based on these results and considerable evidence reported previously, we proposed the hypothesis that targeting mesothelioma stem cells (MSC) might be able to inhibit cancer cell repopulation during the intervals of chemotherapy (Fig. 1d).

Tumor incidence in syngeneic mice generated from surviving mesothelioma cells after $\gamma$-ray irradiation compared with tumors induced by untreated tumor cells Both murine mesothelioma AB12 and RN5 cells were irradiated with 15Gy $\gamma$-ray and surviving cells (3 days post-radiation) were injected into the respective syngeneic mice. Interestingly, the tumor incidence resulting from the injection of surviving irradiated AB12 (Fig. 2a \& b) or RN5 cells (Fig. 2c \& d) was of similar magnitude in comparison to the tumor incidence observed with a 10-fold higher load of the untreated (parental) cells. For instance, $1 \times 10^{5}$ irradiated AB12 or RN5 cells resulted in a similar tumor incidence as with $1 \times 10^{6}$ of untreated AB12 or RN5 cells (Fig. 2a \& c); if the number of irradiated cells was decreased to $1 \times 10^{4}$, the tumor incidence was quite similar to that observed after injection of $1 \times 10^{5}$ untreated cells in both cell lines (Fig. 2b \& d). Besides tumor incidence, also tumor growth (size determined at different time points) in mice after challenging with 10-times less of the irradiated cells was also quite similar as with the higher load of untreated cells (Fig. 2e \& f, compare red and green curves, as well as blue and orange curves). Results with either AB12 or RN5 cells were nearly identical.

\section{Expression of CSC-associated genes was up-regulated in AB12 and RN5 cells after treatment with chemotherapy or radiation}

Total RNA derived from surviving AB12 and RN5 cells after treatment with either cisplatin or $\gamma$-ray radiation was used to perform quantitative real-time PCR. Genes of interest were selected based on available literature previously reporting on genes likely associated with CSC in malignant mesothelioma. The treatments were the same as before: cisplatin $(1$ or $5 \mu \mathrm{g} / \mathrm{ml}$ ) or $\gamma$-ray radiation ( 5 or $15 \mathrm{~Gy})$. Some of the genes that were significantly upregulated, included CD24, CD90, CD68, CD117 in both cell lines, while other genes tended to be upregulated particularly in AB12 cells, while differences did not reach significance in RN5 cells (CD133, uPAR, CD34, Bmi-1). The genes CD24, CD117 and CD68 showed increased expression after either treatment (Additional file 1: Figure S1).

Establishment of transduced RN5-EOS-Puro2 cells and confirmation of some stemness properties

RN5-EOS-Puro2 cells were generated as reported before using a lentiviral plasmid construct [25]. Transduced RN5-EOS-Puro2 cells subjected to selection with puromycin for 2 weeks yielded a cell subpopulation highly enriched in GFP-positive $\left(\mathrm{GFP}^{+}\right)$cells assuming putative MSC (Fig. 3a); the gradual increase of $\mathrm{GFP}^{+}$cells over time is demonstrated by FACS as shown in Fig. 4b. These highly-enriched MSC were obtained after puromycin treatment for at least 2-3 weeks; then the fraction of the strongly green $\mathrm{GFP}^{+}$population reached approximately 65-85\% as quantified by FACS (Fig. 3b). Serial numbers of puromycin-selected cells (50, 100 and 500 cells/well) were grown in ultra-low adherent 24-well plates; 3D spheres (mesospheres) were formed at approximately 7 days of culture consisting of cells with strong GFP fluorescence (Fig. 3c). Highly enriched MSC $\mathrm{GFP}^{+}$cells were fixed and immunostained for Oct4. Positive staining for Oct4 was observed in the nucleus (Fig. 3d).

\section{Mesothelioma stem cells (MSC) are more resistant to} chemotherapy or radiation treatment in vitro

A majority of the highly enriched MSC RN5-EOS-Puro2 cells after puromycin selection for 14 days were GFPpositive (as shown in the histogram as the blue population) compared with unselected RN5-EOS parental cells (red population) (Fig. 4a). Treatment with cisplatin or 

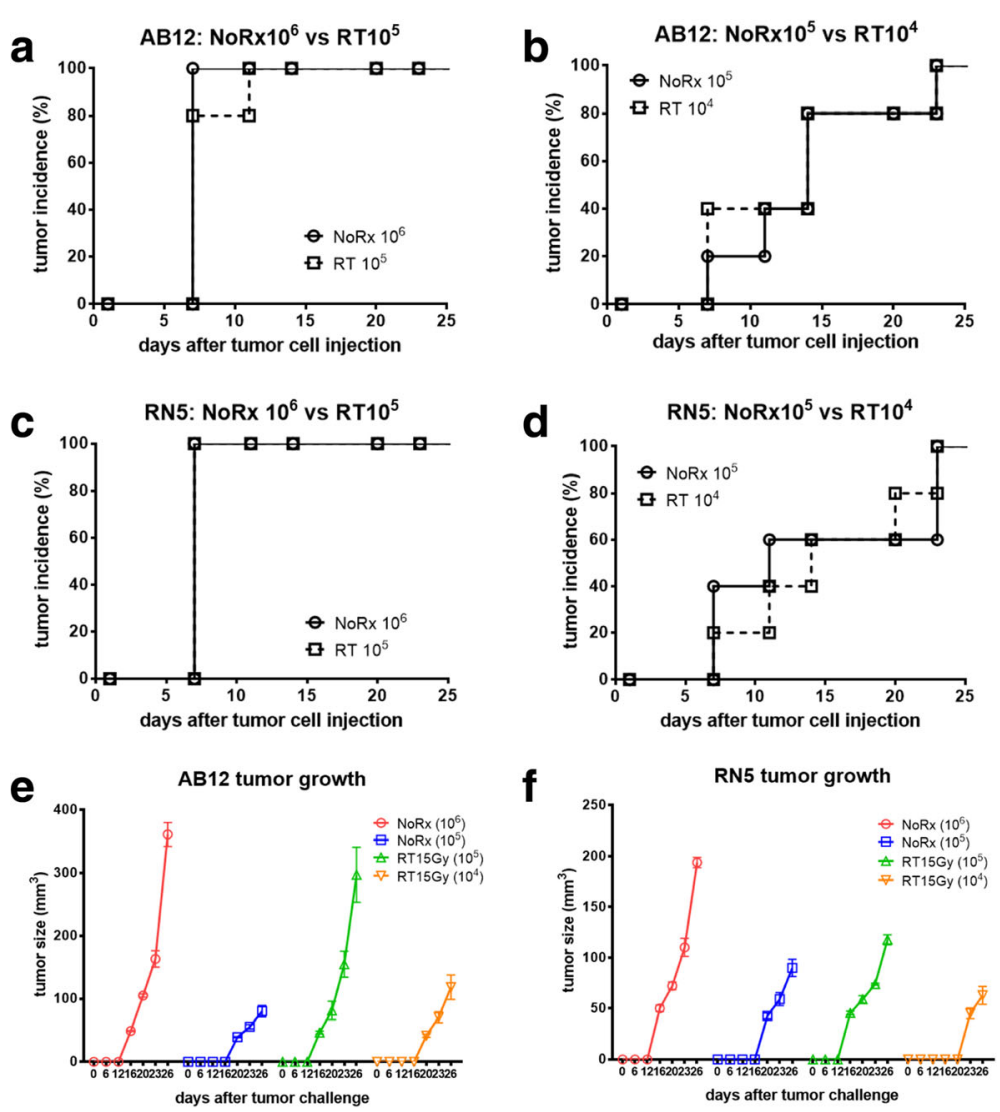

Fig. 2 Tumor incidence in syngeneic mice resulting from injection of MM cells, either parental (no treatment; NoRx) or cells surviving $\gamma$-ray irradiation (RT). AB12 (a, b) and RN5 (c, d) cells were irradiated with 15 Gy $\gamma$-ray; surviving cells were used for s.c. injections in the right flank of mice ( $n=5 / g r o u p)$. The number of injected cells are indicated on the graphs. Surviving irradiated AB12 or RN5 cell injection resulted in the same tumor incidience with 10 -fold less cells than when injecting the untreated AB12 or RN5 cells. The same results were obtained at two different doses of injected cells. e, f Start of tumor development was considered, when tumors become palpable; measurements of the two maximum perpendicular diameters were used to calculate the tumor size

$\gamma$-ray radiation did not result in a dramatic change in the highly enriched MSC even though when given at higher doses of cisplatin $(5 \mu \mathrm{g} / \mathrm{ml})$ or in combination with $\gamma$-ray radiation RT5Gy, suggesting that they were more resistant to chemoradiation (Fig. 4b). In line with the presumed increased chemo- and/or radiation resistance of $\mathrm{GFP}^{+}$cells, the fraction of green cells increased in the parental RN5-EOS population subjected to cisplatin $(1 \mu \mathrm{g} / \mathrm{ml})$, radiation (5Gy) or both (Fig. 4c). Under the selected conditions, it was evident that cisplatin had a stronger effect in sparing the $\mathrm{GFP}^{+}$cells. A similar experiment carried out with RN5-EOS-Puro2 cells consisting of mostly green cells gave essentially identical results; however the magnitude of the effect was much smaller, since most cells consisted of already resistant cells. Only in the groups treated with cisplatin, a decrease of non-green cells, i.e., a higher fraction of $\mathrm{GFP}^{+}$ cells was evident (Fig. 4d). We also compared the morphology of the highly enriched MSC with or without treatment by confocal microscopy. GFP fluorescence signals were similar in untreated MSC (NoRx) in comparison to MSC after treatment with $\gamma$-ray radiation 15Gy (RT15Gy) or cisplatin (Cis) $5 \mu \mathrm{g} / \mathrm{ml}$. This indicates that radiation has no direct effect on expression levels or intracellular localisation of GFP (Fig. 4e).

\section{Gene profile associated with mesothelioma and mesothelioma stem cells (MSC)}

With the aim of finding differentially expressed genes (gene signatures) for different types of cells of mesothelial origin and for different treatments, a gene screening strategy was developed by comparing various groups (NoRx, Cis, RT and MSC) as depicted in Fig. 5a. Overall differences of gene expression were determined by principal component assay (PCA) mapping, which separated very well, indicating significant differences between groups (Fig. 5b). The number of genes with at least a 2 -fold change and $p$ values less than 0.05 including both up- and down-regulated genes among the 4 groups is shown in the bar graph and Venn diagrams 


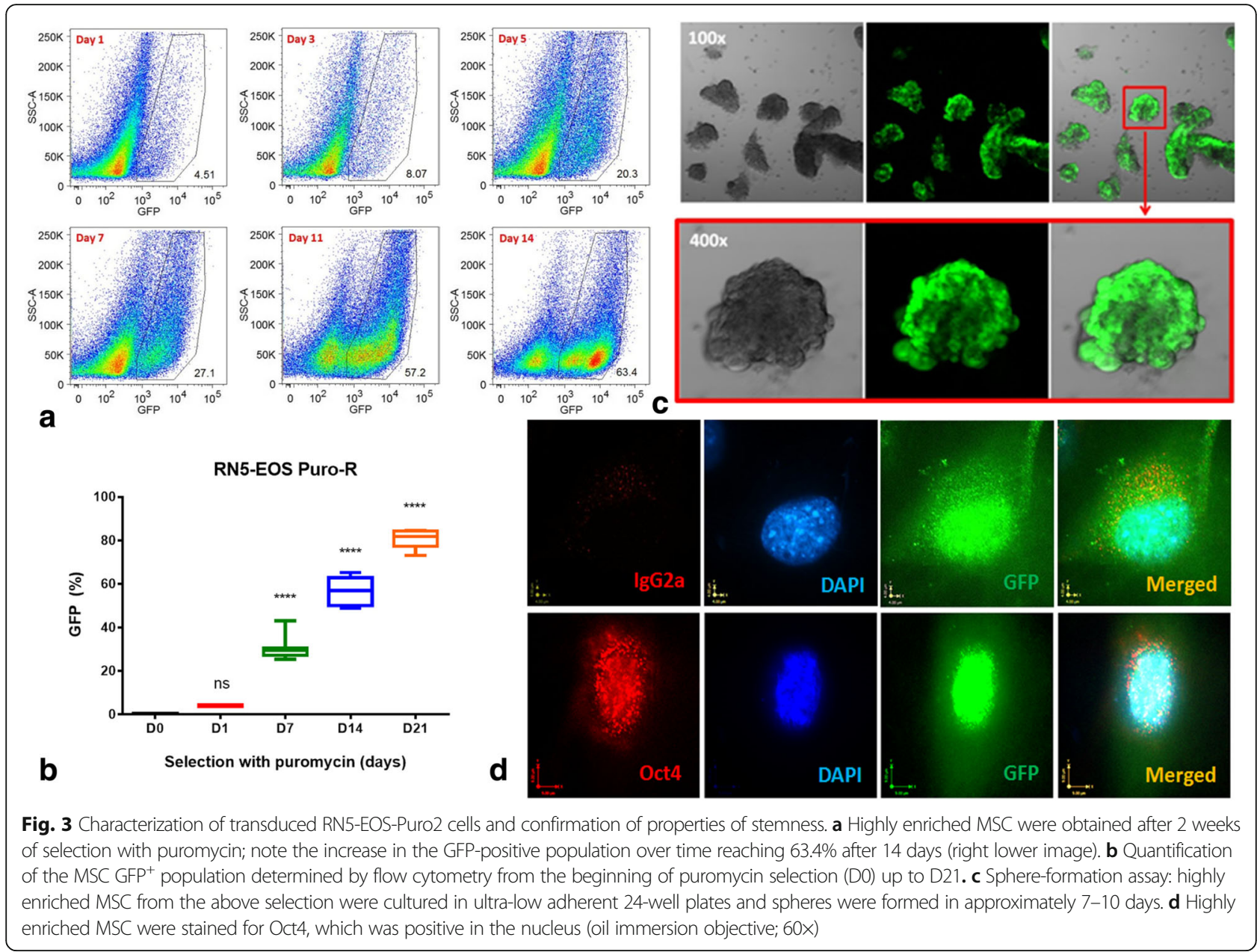

(Fig. 5c \& d). The largest difference (1901 genes) in gene expression levels was observed between the parental untreated RN5 cells and highly MSC-enriched RN5-EOSPuro 2 cells. The gene difference likely attributed to the critical genes of tumor cells and stem cells may by potential MSC-associated genes. Based on the finding that CSC are more resistant to cisplatin or $\gamma$-ray radiation, one would expect to observe an increase in MSC-state cells; the overlap between NoRx and Cis consisted of 761 genes and between NoRx and RT of 194, and the common genes of all three comparisons among NoRx, Cis, RT and MSC groups were narrowed down to 41 genes (Fig. 5d and Additional file 1: Table S1). A Heatmap of screened genes from the overlapping list in the Venn diagram highlights most likely MSC-associated genes. Two contrary clusters contain the up-regulated and down-regulated genes in MSC or after treatment with chemoradiation of RN5 cells compared with parental RN5 cells (Fig. 5e).

This group of selected genes is most likely associated with the MSC state. We hypothesize that among these genes, one or several might evolve as a biomarker to identify MSC.

\section{Confirmation of the genes of interest by RT-qPCR and flow cytometry}

Confirmation of these genes was determined by quantitative real-time PCR. Gene expression of Tnfsf18, Serpinb9b, NPPB and Ly6a (Sca-1) were found upregulated significantly after treatment with Cis $0.5 \mu \mathrm{g} / \mathrm{ml}, 1 \mu \mathrm{g} / \mathrm{ml}$ or $\gamma$-ray radiation 5Gy, 10Gy, 10Gy or in combination of Cis $1 \mu \mathrm{g} / \mathrm{ml}$ and RT5Gy (Fig. 5f). Other genes including CD24, CD117, uPAR, and CD133 that were reported previously in mesothelioma were upregulated as well (Fig. 5g).

Preliminary studies have indicated that positive staining for Tnfsf18 and Ly6a was observed in RN5-EOS-Puro2 cells. Peritoneal lavage cells after i.p. injection of RN5 cells stained Tnfsf18 and Sca-1 double-positive (Additional file 1: Figure S2 and unpublished data).

The 41 common genes were screened by comparing the groups NoRx vs Cis, RT and MSC (Additional file 1: Table S1). The upregulated and downregulated genes were separated in a first step. The downregulated gene list was then dropped due to the low number, therefore, we concentrated on upregulated genes. When submitted to gene signature profiling (GSEA) and after ID conversion, 
a

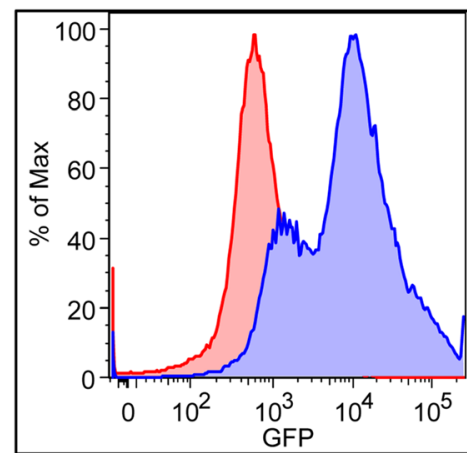

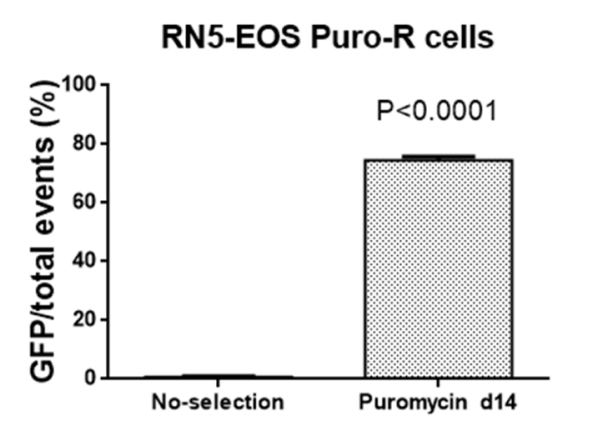

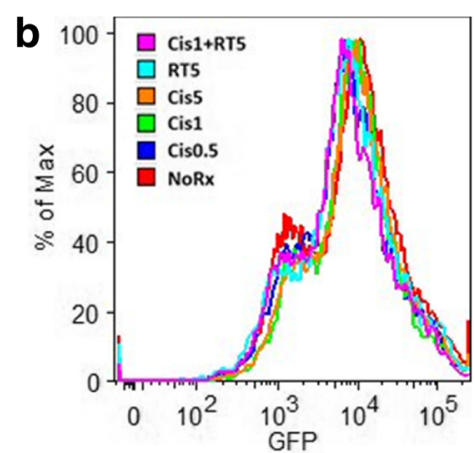

C

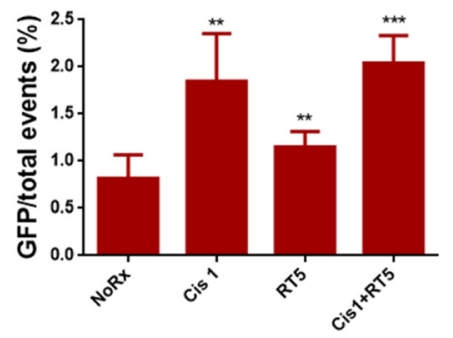

d

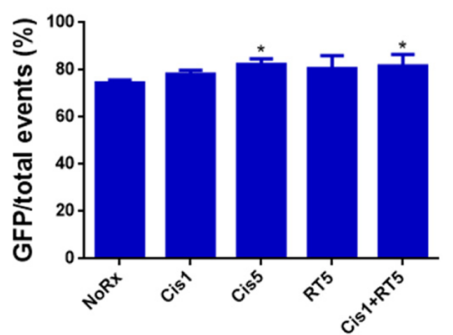

e
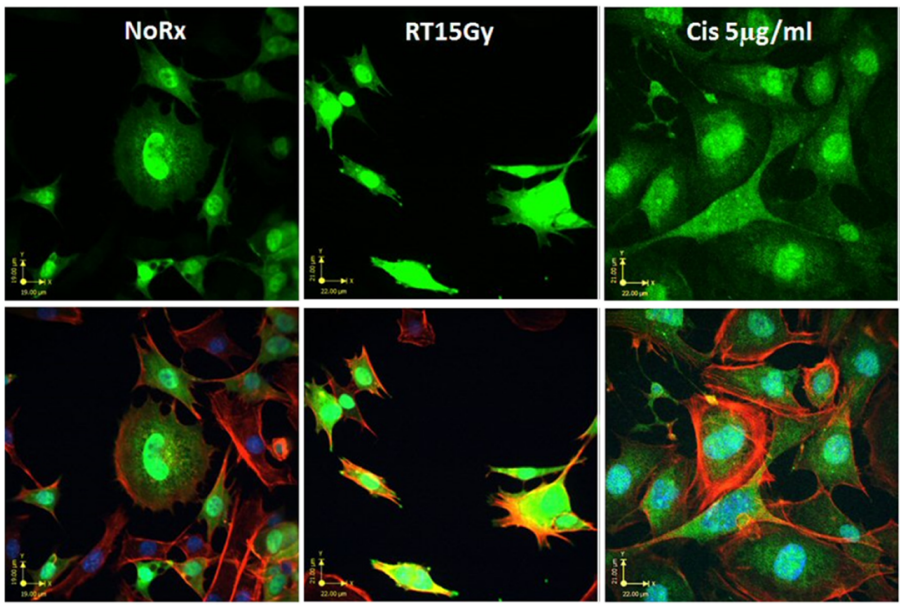

Fig. 4 Mesothelioma stem cells are more resistant to chemotherapy or radiation treatment in vitro. a The majority of highly enriched RN5-EOS-Puro2 cells ( $2 \mathrm{\mu g} / \mathrm{ml}$ for 14 days) were GFP-positive as shown in the histograms (blue curve) if compared with the unselected parental RN5-EOS cells (red curve). $\mathbf{b}$ RN5-EOS-Puro2 cells were treated with cisplatin or $\mathrm{Y}$-ray radiation and were more resistant. $\mathbf{c}$, $\mathbf{d}$ Untreated parental RN5-EOS cells and RN5-EOS-Puro2 cells were treated with cisplatin or $\gamma$-ray radiation. Cisplatin and radiation resulted in significant increases of the GFP-positive cell populations; in the selected MSC-enriched population, only cisplatin (alone or in combination with irradiation) slightly increased the fraction of GFP ${ }^{+}$cells e) RN5-EOS-Puro2 cells express high levels of GFP (green), even after treatment with 15 Gy $\gamma$-ray (RT15Gy) or cisplatin (Cis) 5 Mg/ml, almost similar as is observed in RN5-EOS-Puro2 cells not subjected to any treatment. Actin immunoflurescence is shown for the outline of cells (red) and DAPI was used to stain nuclei (blue). A merged image is shown in the right lower corner

Sca-1 (Ly-6a) was not present in the list of human genes and thus it does not appear in Additional file 1: Table S2. The remaining overlapping genes are shown in Additional file 1: Table S2, where we found that genes upregulated by k-ras are significantly increased.

To evaluate the potential signaling pathways that these genes may be involved in, we first used the identified 41 genes to perform the gene ontology (GO) analysis (Table 1). At the cutoff of FDR $<0.05,7$ pathways related to positive regulation of cell development, differentiation, growth and negative regulation of cell death and apoptosis were identified and NGF and Spp1 may be the dominant drivers of all these pathways (Fig. 6a). To obtain a more stable conclusion of the GO analysis, we expanded the gene list by doing Pearson correlations of the 41 genes with the rest of the genes. At cutoffs of $0.98<r<-0.98$ and $p<0.00001,221$ genes were identified to be significantly correlated with one of the 41 genes. GO analysis confirmed the involvement of pathways related to positive regulation of cell development, differentiation, growth and negative regulation of cell death and apoptosis. Again, NGF and Spp1 play a crucial role in these signaling pathways. In addition, CD44 and PTK2B genes that are closely correlated with NGF signaling were also identified (Fig. 6b and Additional file 1: Table S3).

\section{Discussion}

Current therapies for MPM include cisplatin and pemetrexed-based chemotherapy, hemithoracic fractionated radiation, and surgery [28-30]. However, the efficacy is far from satisfying, even though some improvements have been achieved, and immunotherapy is probably the most 
a

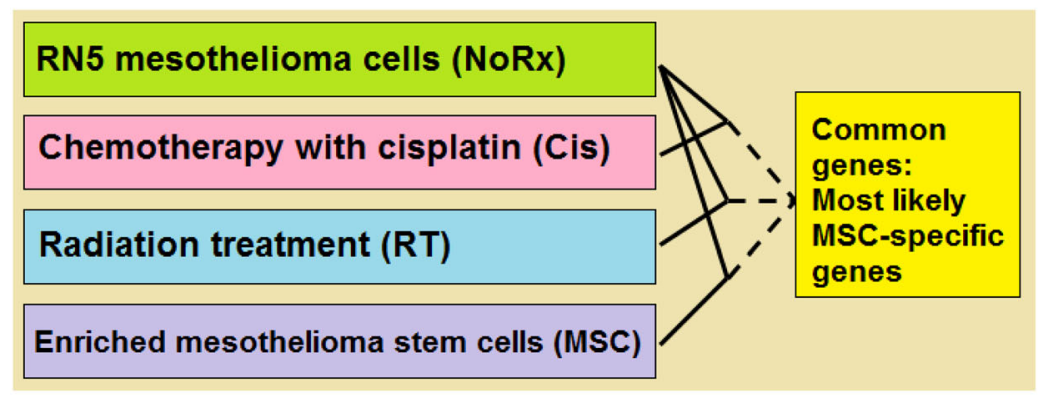

C

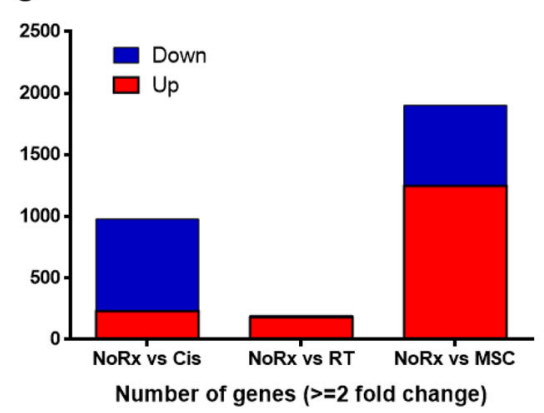

b

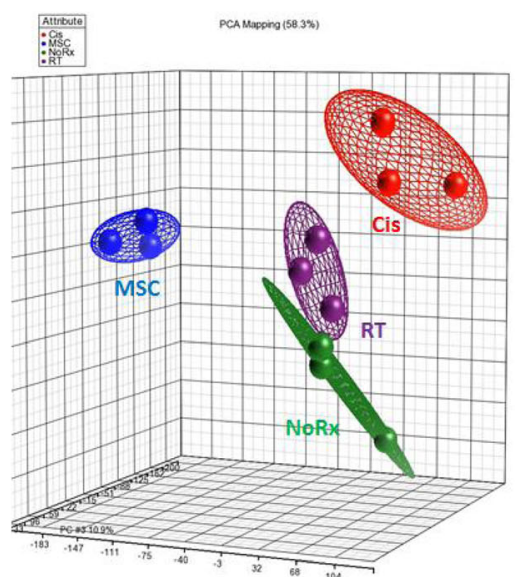

d

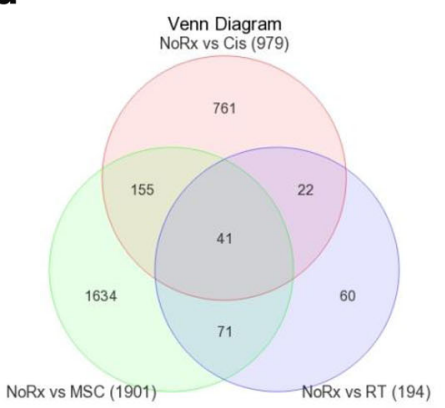

e
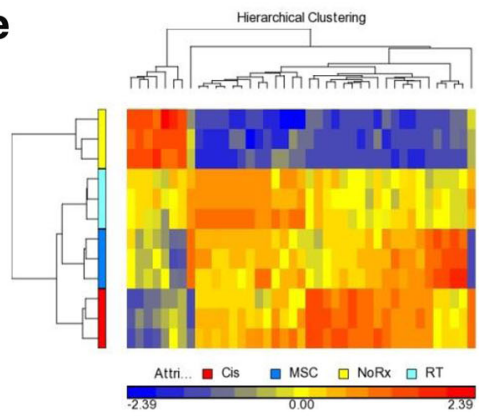

f
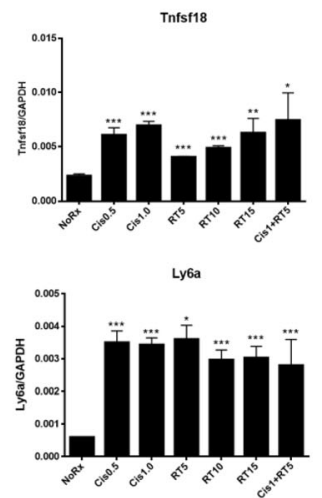

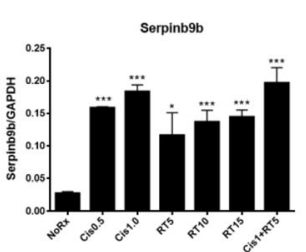

Nppb

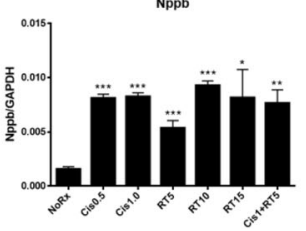

g

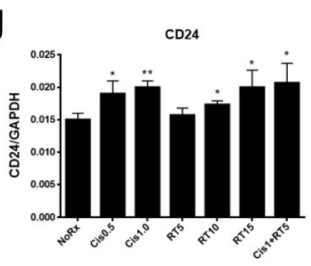

CD133

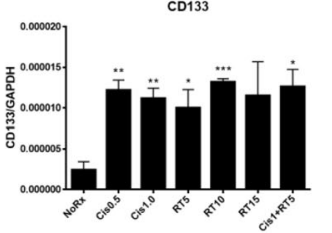

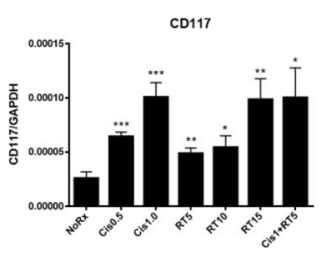

UPA-R (CD87)

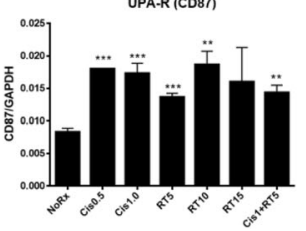

Fig. 5 Mesothelioma stem cell-associated genes. a Screening strategy of mesothelioma stem cell-associated genes by comparing parental RN5 cells with no treatment (NoRx), with cisplatin (Cis), y-ray radiotherapy (RT), and enriched mesothelioma stem cells (MSC); b Overall differentiation of gene expression determined by principal component assay (PCA) mapping; c Total number of genes with a greater than 2-fold change of up- or down-regulation; $\mathbf{d}$ Venn diagram showing the overlapping genes of the 3 comparisons as depicted in (a); e Heatmap of gene expression in the 4 groups (NoRx, Cis, RT and MSC) as screened in the Venn diagram, which most likely contains mesothelioma-associated stem cell genes; f Novel genes including Tnfsf18, Serpinb9b, Ly6a and Nppb are confirmed to be upregulated by RT-qPCR; $\mathbf{g}$ Known genes CD24, CD117, CD133 and UPAR (CD87) are upregulated, as well as after treatment with chemoradiation. The experiment was carried out twice. The ratio of each gene to the house-keeping gene GAPDH is presented as mean \pm SD. ${ }^{*} P<0.05,{ }^{*} P<0.01,{ }^{* * *} P<0.001$

promising strategy to control this disease through modulation of the immune response [31]. For instance, systemic blockade of immune checkpoints such as CTLA-4, PD-1 and its ligands PD-L1/2 has shown significant antitumor effects in certain cancers including mesothelioma [11, 32]. In our experience, we found that EPP performed after a short course of high dose hemithoracic radiation resulted in better outcome for the patients with an epithelioid MM subtype. Evidence in our laboratory has shown that the benefit is very likely due to the activation of a specific immune response against the tumor by the high dose radiation $[8,14,33]$.

Cancer cells that are not killed by conventional cytotoxic therapy will repopulate the tumor and lead to treatment resistance [34]. Repopulation between treatments is likely 
Table 1 After expansion by Pearson, the 41 genes correlated with the rest 211 genes and involved in 32 pathways

\begin{tabular}{|c|c|c|c|}
\hline Number & Pathway ID & Pathway & $\mathrm{FDR}^{\mathrm{a}}$ \\
\hline 1 & GO:0008299 & Isoprenoid biosynthetic process & 0.002134 \\
\hline 2 & GO:0051346 & Negative regulation of hydrolase activity & 0.002385 \\
\hline 3 & GO:0006644 & Phospholipid metabolic process & 0.003211 \\
\hline 4 & GO:0006916 & Anti-apoptosis & 0.00327 \\
\hline 5 & GO:0043086 & Negative regulation of catalytic activity & 0.003652 \\
\hline 6 & GO:0042976 & Activation of Janus kinase activity & 0.004027 \\
\hline 7 & GO:0018106 & Peptidyl-histidine phosphorylation & 0.004027 \\
\hline 8 & GO:0006417 & Regulation of translation & 0.006019 \\
\hline 9 & GO:0031399 & Regulation of protein modification process & 0.006455 \\
\hline 10 & GO:0010608 & Posttranscriptional regulation of gene expression & 0.006471 \\
\hline 11 & GO:0031124 & mRNA 3'-end processing & 0.006525 \\
\hline 12 & GO:0040008 & Regulation of growth & 0.007398 \\
\hline 13 & GO:0008202 & Steroid metabolic process & 0.007429 \\
\hline 14 & GO:0008361 & Regulation of cell size & 0.007517 \\
\hline 15 & GO:0045793 & Positive regulation of cell size & 0.007545 \\
\hline 16 & GO:0045927 & Positive regulation of growth & 0.007662 \\
\hline 17 & GO:0006066 & Alcohol metabolic process & 0.007722 \\
\hline 18 & GO:0001932 & Regulation of protein phosphorylation & 0.00775 \\
\hline 19 & GO:0043154 & Negative regulation of caspase activity & 0.007818 \\
\hline 20 & GO:0016049 & Cell growth & 0.007857 \\
\hline 21 & GO:0043066 & Negative regulation of apoptosis & 0.007891 \\
\hline 22 & GO:0008610 & Lipid biosynthetic process & 0.007913 \\
\hline 23 & GO:0030307 & Positive regulation of cell growth & 0.008 \\
\hline 24 & GO:0007259 & JAK-STAT cascade & 0.008302 \\
\hline 25 & GO:0060548 & Negative regulation of cell death & 0.009413 \\
\hline 26 & GO:0001558 & Regulation of cell growth & 0.00978 \\
\hline 27 & GO:0043069 & Negative regulation of programmed cell death & 0.009786 \\
\hline 28 & GO:0051336 & Regulation of hydrolase activity & 0.009791 \\
\hline 29 & GO:0016126 & Sterol biosynthetic process & 0.01 \\
\hline 30 & GO:0008203 & Cholesterol metabolic process & 0.01 \\
\hline 31 & GO:0006695 & Cholesterol biosynthetic process & 0.01 \\
\hline 32 & GO:0016125 & Sterol metabolic process & 0.01 \\
\hline
\end{tabular}

At cutoffs of $0.98<r<-0.98$ and $p<0.00001,221$ genes were identified to be significantly correlated with one of the 41 genes. ${ }^{\mathrm{a}} F D R$ False discovery rate. FDR $<0.01$

one of the mechanisms to explain why some cancers respond initially to chemotherapy, but become resistant to continued treatment [35]. Therefore, selective inhibition of cancer cell repopulation might overcome drug resistance. Our results provide evidence that the proportion of MSC increases after chemoradiation, and that MSC are more resistant to the treatment of chemoradiation in murine mesothelioma. CSC may play critical roles in the process of cancer cell repopulation, however, biomarkers to identify CSC remain elusive [36-38]. Until recently the transcription factors Oct4, Sox2, and Nanog have been considered playing essential roles in early development and for the propagation of undifferentiated embryonic stem cells (ESC) in culture [39]. Recent results provide new insights into the transcriptional regulation of stem cells and reveal how Oct4, Sox2, and Nanog contribute to pluripotency and self-renewal [40]. A new technique was developed to transduce transcription factor target genes into fibroblasts, so as to transform the property of fibroblasts to induced pluripotent stem cells (iPS) [41]. More strikingly, iPS reporter cell lines were generated for the identification and selection of pluripotent stem cells in vitro [24, 42]. Based on the above progress, we developed the RN5-EOS murine cell line, by transducing the EOS into RN5 cells with lentiviral vector. RN5-EOS cells with a GFP reporter can be selected by puromycin, so as to 


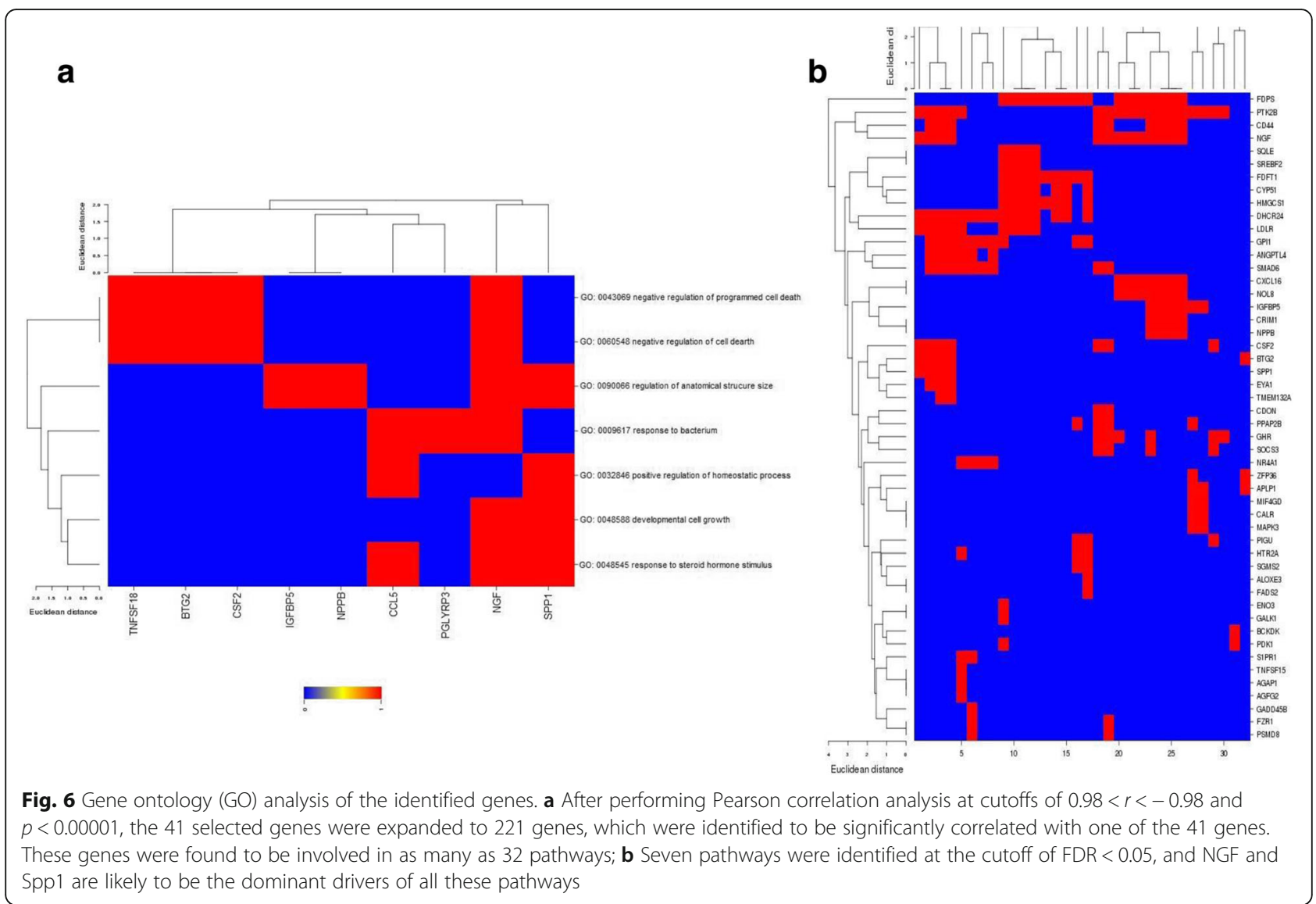

achieve a highly enriched population of stem cells. RN5 is a murine mesothelioma cell line, which was recently established after exposure to asbestos fibers in a C57BL/6 background mouse in our laboratory [27].

Due to availability of highly enriched MSC, it would be beneficial to design novel strategies targeting MSC. However, identification of MSC is still a big challenge [21]. By using microarray analysis, we compared MSC with RN5 parental cells after treatment with chemoradiation and found a group of genes that are most likely MSC-specific genes. In future studies, the functions of these genes need to be confirmed. Only a few genes such as $n p p b$ have been reported to play a critical role in ESC signaling pathways [43]. Another gene $L y 6 a$, also known as Sca-1, has been identified as a CSC marker [44]. Other genes have not yet been demonstrated to be associated with stem cell properties.

Our preliminary results showed that tumor-specific $\mathrm{T}$ cells can be activated by co-culturing splenocytes derived from RN5-bearing mice after pulsation with whole cell lysates of parental RN5 or MSC-enriched RN5-EOSPuro2 cells. We found that splenocytes derived from RN5 tumor-bearing mice had a significantly higher rate of $\mathrm{T}$ cell proliferation (identified by Ki67 staining) after pulsation of lysates $(p=0.0001)$. More encouragingly,
RN5-EOS-Puro2 cell lysate resulted in a similar response of $\mathrm{T}$ cell proliferation with pan-antigens of RN5 cell lysate $(p=0.0224)$ (Additional file 1: Figure S3). It is required to identify MSC-specific markers.

Availability of highly enriched MSC made it possible to prepare a whole MSC lysate vaccine to enhance specific immunity against mesothelioma cells. Immune therapy targeting MSC in combination with conventional cytotoxic therapy is assumed to potentially improve the efficacy of treatment against this disease. This approach would open new avenues to mesothelioma treatment and also be feasible for other types of cancer.

In the future, we expect to combine this approach with removing the brake of immune checkpoints, to maximally boost the immune response to target MSC, and eventually to improve the efficacy of mesothelioma treatment. Evidence in our AB12 mesothelioma model indicated that systemic blockade of the immune checkpoints CTLA-4 and PD-1 in combination with chemo- or radiation therapy did result in tumor growth delay through enhancing antitumor immunity, such as activating $\mathrm{T}$ cells and decreasing Treg [14]. However, only few studies looked at the impact of CSC in mesothelioma. Programmed DC vaccine with MSC-specific peptides or whole cell lysates might have a powerful 
impact on MSC, since MSC are resistant to chemotherapy or radiation, but less resistant to immunotherapy.

In vitro assay of tumor-specific immune responses showed that after overnight co-culture of splenocytes derived from RN5-bearing mouse spleen pulsed with or without RN5 cell lysate or enriched RN5-EOS-Puro2 cell lysate, tumor specific $\mathrm{T}$ cell activation and proliferation were found remarkably increased compared with naïve splenocytes, suggesting that specific anti-tumor immune response can be enhanced by pulsation with both mesothelioma cell lysate and MSC whole cell lysate. If MSC markers could be confirmed, we would be able to monitor specific immunity against MSC and to design specific immunotherapy targeted against MSC.

The first DC vaccine was approved by the FDA in 2014 [20]. Intratumoral delivery of a DC vaccine was confirmed to be effective, especially after the tumor was treated with chemotherapy or radiation. Tumor-associated antigens (TAA) released from dead tumor cells are captured and processed by $\mathrm{DC}$, and presented to naïve T cells. Activated $\mathrm{T}$ cells start migrating and trafficking to recognize tumor cells and eliminate them [45]. Immature DCs become mature after uptake of TAA. Mature DCs also release cytokines including IL-12 and IFN- $\gamma$ that are able to kill tumor cells directly or indirectly by inhibiting tumor angiogenesis [46, 47]. A recent study had evaluated the specificity of DCs for breast cancer stem cells (BCSCs) in vitro and in vivo, and immature DCs were primed with BCSC-derived antigens to generate mature DCs. Modified DCs may be a promising therapy for treating drugresistant cancer cells as well as CSC [48]. Also, MSC-associated genes could be introduced or eliminated to demonstrate their roles in maintaining stemness by genetic manipulation using the CRISPR technique [49].

MSC-specific markers also make it possible to design novel target therapies against MSC by neutralization with monoclonal antibodies. More promisingly chimeric antigen receptor T cells (CAR-T) may be modulated by using MSCspecific antigens [50]. Functional assays could be performed through manipulating individual genes.

\section{Conclusions}

In conclusion, by further verifying the MSC-specific markers based on the group of genes screened by microarray, target therapy or specific immunotherapy may be designed thereafter. The enriched MSC can be used to prepare whole cell MSC lysate for vaccine alone or pulsation of DC derived from bone marrow. More interestingly, specific immune responses could be monitored, once MSC markers are determined. This novel DC vaccine would be able to activate T cells that specifically recognize MSC and eliminate them. It might be promising to focus on targeting MSC through immune modulation by specific $\mathrm{T}$ cell response in murine mesothelioma models. This work opens a new avenue for mesothelioma treatment as well as for other types of cancer.

\section{Additional file}

Additional file 1: Figure S1. Expression of CSC-associated genes up-regulated in AB12 and RN5 cells after cisplatin treatment or radiation. Table $\mathbf{S 1}$. The selected gene list with 2 or more fold change in comparison with untreated RN5 cells. Figure S2. Tumor-associated macrophages may share the property of mesothelioma stem cells. Table S2. Selected genes of potential murine mesothelioma stem cells overlapped with human gene signature profiling (GSEA). Table S3. GO signaling pathways associated with the selected 41 genes. Figure S3. In vitro assay of tumorspecific T cell proliferation determined by flow cytometry. (PDF 666 kb)

\section{Abbreviations}

Cis: Cisplatin; CSC: Cancer stem cells; EPP: Extrapleural pneumonectomy; GO: Gene Ontology; iPS: induced pluripotent stem cells; MPM: Malignant pleural mesothelioma; MSC: Mesothelioma stem cells; N: Naïve peritoneum; NoRx: No treatment; RT: Radiotherapy; TAC: Transcriptome Analysis Console; Treg: Regulatory $\mathrm{T}$ cell

\section{Acknowledgments}

We would like to thank all funding supports, and technical supports from Microarray Facility, The Centre for Applied Genomics, The Hospital for Sick Children, Toronto. We also thank the Animal Resources Centre and Flow Cytometry Facility, University Health Network, Toronto, Canada.

\section{Funding}

This work was supported by the Princess Margaret Hospital Foundation (PMHF, Canada) and the Mesothelioma Research Foundation (MRF, Canada), and the Swiss National Science Foundation (SNF) Sinergia grant CRSII3 \#147697 (Switzerland). This work was also supported by the Mesothelioma Applied Research Foundation (MARF, USA).

All Foundations had no role in this manuscript other than providing funding support.

Availability of data and materials

The datasets used and/or analysed during the current study are available from the corresponding author on reasonable request.

\section{Authors' contributions}

Overall design, experiments and result analysis, and manuscript drafting: LW. Supervisor and corresponding author, and study design, result analysis and discussion, and manuscript review and correction: MdP. Technical support, animal experiments and discussion: WB, ZY, LP, MK, MLC, YZ. Collaborators of Sinergia project sponsored by Switzerland and also supervision of this study, study design, result analysis and discussion, and manuscript review and correction: EFB, BS. Data analysis of microarray results and signalling pathways: CQZ. All authors have read and approved the manuscript.

Ethics approval and consent to participate

The Animal Use Protocol (AUP\# 3399) was approved by the Animal Resources Centre of University Health Network (UHN), Toronto, Canada.

Consent for publication

All authors have read and approved the manuscript to be published by BMC Cancer journal.

\section{Competing interests}

The authors declare that they have no competing interests.

\section{Publisher's Note}

Springer Nature remains neutral with regard to jurisdictional claims in published maps and institutional affiliations. 


\section{Author details}

'Division of Thoracic Surgery, Latner Thoracic Surgery Laboratories, University Health Network, Toronto, ON, Canada. ${ }^{2}$ Princess Margaret Cancer Centre, University Health Network, Toronto, ON, Canada. ${ }^{3}$ Department of Medicine, Unit of Anatomy, University of Fribourg, $\mathrm{CH}-1700$ Fribourg, Switzerland. ${ }^{4}$ INSERM, U1162, Génomique Fonctionnelle des Tumeurs Solides, 27 rue Juliette Dodu, 75010 Paris, France. ${ }^{5}$ Laboratory of Molecular Oncology, University Hospital Zurich, University of Zurich, 8044 Zürich, Switzerland. ${ }^{6}$ Division of Thoracic Surgery, Toronto Mesothelioma Research Program, Toronto General Hospital, 9N-961, 200 Elizabeth St, Toronto, ON M5G 2C4, Canada.

Received: 15 November 2017 Accepted: 9 April 2018 Published online: 27 April 2018

\section{References}

1. Kanarek MS. Mesothelioma from chrysotile asbestos: update. Ann Epidemiol. 2011;21(9):688-97.

2. Robinson BW, Lake RA. Advances in malignant mesothelioma. N Engl J Med. 2005;353(15):1591-603.

3. Vogelzang NJ, et al. Phase III study of pemetrexed in combination with cisplatin versus cisplatin alone in patients with malignant pleural mesothelioma. J Clin Oncol. 2003;21(14):2636-44.

4. de Perrot $\mathrm{M}$, et al. Risk factors for major complications after extrapleural pneumonectomy for malignant pleural mesothelioma. Ann Thorac Surg. 2008:85(4):1206-10.

5. de Perrot $\mathbf{M}$, et al. Impact of lymph node metastasis on outcome after extrapleural pneumonectomy for malignant pleural mesothelioma. J Thorac Cardiovasc Surg. 2007;133(1):111-6.

6. de Perrot $\mathrm{M}$, et al. Trimodality therapy with induction chemotherapy followed by extrapleural pneumonectomy and adjuvant high-dose hemithoracic radiation for malignant pleural mesothelioma. J Clin Oncol. 2009;27(9):1413-8.

7. Ribi K, et al. Individual versus standard quality of life assessment in a phase II clinical trial in mesothelioma patients: feasibility and responsiveness to clinical changes. Lung Cancer. 2008;61(3):398-404.

8. Cho BC, et al. A feasibility study evaluating surgery for mesothelioma after radiation therapy: the "SMART" approach for resectable malignant pleural mesothelioma. J Thorac Oncol. 2014;9(3):397-402.

9. Anraku M, et al. Synergistic antitumor effects of regulatory $T$ cell blockade combined with pemetrexed in murine malignant mesothelioma. J Immunol. 2010;185(2):956-66.

10. Wu L, et al. Tumor cell repopulation between cycles of chemotherapy is inhibited by regulatory T-cell depletion in a murine mesothelioma model. J Thorac Oncol. 2011;6(9):1578-86.

11. Wu L, et al. CTLA-4 blockade expands infiltrating T cells and inhibits cancer cell repopulation during the intervals of chemotherapy in murine mesothelioma. Mol Cancer Ther. 2012;11(8):1809-19.

12. Tagawa T, et al. Antitumor impact of interferon-gamma producing CD1drestricted NKT cells in murine malignant mesothelioma. J Immunother. 2013;36(8):391-9.

13. Wu L, et al. Activation of CD1d-restricted natural killer T cells can inhibit cancer cell proliferation during chemotherapy by promoting the immune responses in murine mesothelioma. Cancer Immunol Immunother. 2014; 63(12):1285-96

14. Wu $L$, et al. Targeting the inhibitory receptor CTLA-4 on $T$ cells increased abscopal effects in murine mesothelioma model. Oncotarget. 2015;6(14): $12468-80$.

15. Licun W, Tannock IF. Selective estrogen receptor modulators as inhibitors of repopulation of human breast cancer cell lines after chemotherapy. Clin Cancer Res. 2003;9(12):4614-8.

16. Wu L, Tannock IF. Repopulation in murine breast tumors during and after sequential treatments with cyclophosphamide and 5-fluorouracil. Cancer Res. 2003;63(9):2134-8

17. Fung AS, Wu L, Tannock IF. Concurrent and sequential administration of chemotherapy and the mammalian target of rapamycin inhibitor temsirolimus in human cancer cells and xenografts. Clin Cancer Res. 2009; 15(17):5389-95.

18. Wu L, Tannock IF. Effect of the selective estrogen receptor modulator arzoxifene on repopulation of hormone-responsive breast cancer xenografts between courses of chemotherapy. Clin Cancer Res. 2005;11(22):8195-200.
19. Wu L, Birle DC, Tannock IF. Effects of the mammalian target of rapamycin inhibitor CCl-779 used alone or with chemotherapy on human prostate cancer cells and xenografts. Cancer Res. 2005;65(7):2825-31.

20. Hovden AO, Appel S. The first dendritic cell-based therapeutic cancer vaccine is approved by the FDA. Scand J Immunol. 2010;72(6):554.

21. Prashad SL, et al. GPI-80 defines self-renewal ability in hematopoietic stem cells during human development. Cell Stem Cell. 2015;16(1):80-7.

22. Pasdar EA, et al. Characterisation of mesothelioma-initiating cells and their susceptibility to anti-cancer agents. PLoS One. 2015;10(5):e0119549.

23. Dotse $\mathrm{E}$, Bian $\mathrm{Y}$. Isolation of colorectal cancer stem-like cells. Cytotechnology. 2014;68(4):609-619.

24. Hotta A, et al. EOS lentiviral vector selection system for human induced pluripotent stem cells. Nat Protoc. 2009;4(12):1828-44.

25. Blum W, et al. Stem cell factor-based identification and functional properties of in vitro-selected subpopulations of malignant mesothelioma cells. Stem Cell Reports. 2017;8(4):1005-17.

26. Shahryari A, et al. Two novel splice variants of SOX2OT, SOX2OT-S1, and SOX2OT-S2 are coupregulated with SOX2 and OCT4 in esophageal squamous cell carcinoma. Stem Cells. 2014;32(1):126-34.

27. Blum W, et al. Establishment of immortalized murine mesothelial cells and a novel mesothelioma cell line. In Vitro Cell Dev Biol Anim. 2015;51(7):714-21.

28. Thieke $C$, et al. Long-term results in malignant pleural mesothelioma treated with neoadjuvant chemotherapy, extrapleural pneumonectomy and intensity-modulated radiotherapy. Radiat Oncol. 2015;10:267.

29. de Perrot $M$, et al. Accelerated hemithoracic radiation followed by extrapleural pneumonectomy for malignant pleural mesothelioma. J Thorac Cardiovasc Surg. 2016;151(2):468-73.

30. Wu L, et al. Patient-derived xenograft establishment from human malignant pleural mesothelioma. Clin Cancer Res. 2017;23(4):1060-7.

31. Guazzelli A, et al. Tremelimumab for the treatment of malignant mesothelioma. Expert Opin Biol Ther. 2015;15(12):1819-29.

32. A Potential Immune Therapy for Mesothelioma. Cancer Discov. 2015 5(7):OF14. https://doi.org/10.1158/2159-8290.CD-NB2015-067. Epub 2015 May 8. PMID: 25956959

33. De La Maza L, Wu M, Wu L, Yun H, Zhao Y, Cattral M, McCart A, Cho BJ, de Perrot M. In Situ Vaccination after Accelerated Hypofractionated Radiation and Surgery in a Mesothelioma Mouse Model. Clin Cancer Res. 2017:23(18):5502-5513.

34. Tannock IF. Cancer: resistance through repopulation. Nature. 2015; 517(7533):152-3.

35. Saggar JK, Tannock IF. Chemotherapy rescues hypoxic tumor cells and induces their Reoxygenation and repopulation-an effect that is inhibited by the hypoxia-activated prodrug TH-302. Clin Cancer Res. 2015;21(9):2107-14.

36. Zhao Q, et al. Prognostic value of the expression of cancer stem cell-related markers CD133 and CD44 in hepatocellular carcinoma: from patients to patient-derived tumor xenograft models. Oncotarget. 2016;7(30):47431-47443.

37. Zhou F, et al. Tracing haematopoietic stem cell formation at single-cell resolution. Nature. 2016;533(7604):487-92.

38. Shigeishi $\mathrm{H}$, et al. Maintenance of stem cell self-renewal in head and neck cancers requires actions of GSK3beta influenced by CD44 and RHAMM. Stem Cells. 2013;31(10):2073-83.

39. Wang J, et al. A protein interaction network for pluripotency of embryonic stem cells. Nature. 2006;444(7117):364-8.

40. Boyer $L A$, et al. Core transcriptional regulatory circuitry in human embryonic stem cells. Cell. 2005;122(6):947-56.

41. Woltjen $\mathrm{K}$, et al. piggyBac transposition reprograms fibroblasts to induced pluripotent stem cells. Nature. 2009;458(7239):766-70.

42. Ovchinnikov DA, et al. Transgenic human ES and iPS reporter cell lines for identification and selection of pluripotent stem cells in vitro. Stem Cell Res. 2014;13(2):251-61.

43. Shinde $V$, et al. Simulated microgravity modulates differentiation processes of embryonic stem cells. Cell Physiol Biochem. 2016;38(4):1483-99.

44. Chen W, et al. Malignant transformation initiated by MII-AF9: gene dosage and critical target cells. Cancer Cell. 2008;13(5):432-40.

45. Kratky W, et al. Direct activation of antigen-presenting cells is required for CD8+ T-cell priming and tumor vaccination. Proc Natl Acad Sci U S A. 2011; 108(42):17414-9.

46. Carreno BM, et al. IL-12p70-producing patient DC vaccine elicits TC1polarized immunity. J Clin Invest. 2013;123(8):3383-94.

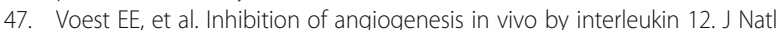
Cancer Inst. 1995;87(8):581-6. 
48. Nguyen ST, et al. Targeting specificity of dendritic cells on breast cancer stem cells: in vitro and in vivo evaluations. Onco Targets Ther. 2015;8:323-34.

49. Kotini AG, et al. Stage-specific human induced pluripotent stem cells map the progression of myeloid transformation to transplantable leukemia. Cell Stem Cell. 2017;20(3):315-28. e7

50. Lynn RC, et al. High-affinity FRbeta-specific CAR T cells eradicate AML and normal myeloid lineage without HSC toxicity. Leukemia. 2016;30(6):1355-64.

Ready to submit your research? Choose BMC and benefit from:

- fast, convenient online submission

- thorough peer review by experienced researchers in your field

- rapid publication on acceptance

- support for research data, including large and complex data types

- gold Open Access which fosters wider collaboration and increased citations

- maximum visibility for your research: over $100 \mathrm{M}$ website views per year 